\title{
Improving Postpartum Haemorrhage Management Using Simulation in Senegal: Midterm Results
}

\section{Mamour Gueye*, Moussa Diallo, Mame Diarra Ndiaye Gueye, Omar Gasama, Abdoul Aziz Diouf, Mouhamadou Mansour Niang, Mohamed Diadhiou, Astou Coly Niassy, Serigne Modou Kane Gueye, Marie Edouard Faye Dieme, Magatte Mbaye, Philippe Marc Moreira, Alassane Diouf, Jean Charles Moreau}

Gynecologic and Obstetric Clinic, Aristide Le Dantec Teaching Hospital, Cheikh Anta Diop University, Dakar, Senegal

Email: *mamourmb@yahoo.fr

How to cite this paper: Gueye, M., Diallo, M., Gueye, M.D.N., Gasama, O., Diouf, A.A., Niang, M.M., Diadhiou, M., Niassy, A.C., Gueye, S.M.K., Dieme, M.E.F., Mbaye, M., Moreira, P.M., Diouf, A. and Moreau, J.C. (2017) Improving Postpartum Haemorrhage Management Using Simulation in Senegal: Midterm Results. Open Journal of Obstetrics and Gynecology, 7, 1292-1299.

https://doi.org/10.4236/ojog.2017.713132

Received: November 20, 2017

Accepted: December 19, 2017

Published: December 22, 2017

Copyright (c) 2017 by authors and Scientific Research Publishing Inc. This work is licensed under the Creative Commons Attribution International License (CC BY 4.0).

http://creativecommons.org/licenses/by/4.0/

\begin{abstract}
Objective: To assess a training approach in Emergency Obstetric and Neonatal Care (EmONC) to strengthen skills of healthcare providers and reduce maternal mortality. Materials and methods: The approach was based on the skills training using the so-called "humanist" method and "life saving skills". Simulated practice took place in the classroom through thirteen clinical stations summarizing the clinical skills on EmONC. The evaluation was done in all phases and the results were recorded in a database to document the progress of each learner. Results: We trained 432 providers in 10 months. The increase in technical achievements of each participant was documented through a database. The combination of training based on the model "learning by doing" has ensured learning and mastering all EmONC skills particularly postpartum haemorrhage management and reduced missed learning opportunities. Conclusion: The impact of training on postpartum haemorrhage management and maternal mortality is a major challenge in terms of prospects.
\end{abstract}

\section{Keywords}

Emergency Obstetric Care, Postpartum Haemorrhage, Training, Simulation

\section{Introduction}

Maternal mortality, which is the most extreme tip of the existing inequality between women in poor and rich countries, remains very high in sub-Saharan Af- 
rica. While the majority of pregnancies and births occur without incident, about $15 \%$ of all pregnant women will experience a potentially life-threatening complication requiring skilled care. Haemorrhage is the leading cause. The introduction of the concept of Emergency Obstetric and Neonatal Care (EONC) will contribute to the reduction of maternal and infant mortality and morbidity by better monitoring of pregnancy, childbirth and postpartum, early detection and appropriate treatment of the morbid factors and pathologies encountered, hence the need to strengthen the skills of health workers in this area. Conventional training in EONC often combines theoretical training in the classroom with the limitations linked to the fact that emergencies are not programmable for learning during the training session.

The objective of this work was to present an innovative approach to continuing education in EONC, focusing on the management of postpartum haemorrhage in Senegal, the general principle of which was to master essential gestures in simulated practice in classroom before practicing in a real situation, all supported by a continuous evaluation of the performance of the provider. The approach was based on competencies using the "humanist" training modelled by JHPIEGO [1] and the life-saving skills developed since 2007 by the Liverpool School of Tropical Medicine and the Royal College of Obstetricians and Gynaecologists [2].

\section{Methodology}

\subsection{Preliminaries}

The aim of this training was to prepare participants for the 5 major causes of maternal mortality (bleeding, infections, high blood pressure, dystocia and complications of abortion) and than neonatal asphyxia. It took place in two phases: a first phase of six to ten days in the form of a seminar in the classroom and a second phase in the form of two formative supervisory visits lasting two days at the provider's working place. After an evaluation of the training needs of the EONC, a literature search made it possible to develop standardized tools (trainer's manual, learner's booklet, learning sheets and checklist) that have been validated by the Ministry of Education and Health and development partners (Belgian Technical Cooperation, UNFPA). The trainers were gynaecologists and obstetricians, teachers at the University of Dakar, who were trained as trainers in a Senegalese institution, capitalizing on a large experience of training based on competence in a French-speaking country, the Center for Training, Research and Advocacy in Reproductive Health.

The participants were midwives and nurses working in Dakar maternity hospitals in the capital and inland areas, some of which were $800 \mathrm{~km}$ from the capital. They were chosen mainly because they worked alone without a doctor.

We obtained the consent of the Ethics Committee of the hospital for this study. We analysed the results obtained in the form of average per evaluation stage (initial, mid-stage and final) and projected on a diagram to assess the ag- 
gregation.

\subsection{Pedagogic Acquisition Method}

The approach was based on competencies using the "humanist" training modelled by JHPIEGO [1] and the life-saving skills developed since 2007 by the Liverpool School of Tropical Medicine and the Royal College of Obstetricians and Gynaecologists [2]. The simulated practice took place in the classroom through clinical stations in which the different clinical skills related to the EONC were developed. At each station, an initial assessment of the participant was carried out, which enabled him to assess his level of competence. A trainer demonstrated competence and then mentored the participant to the master's level. Each participant had to validate the skill on one station before moving on to the next. A leaflet describing the steps of each clinical procedure allowed the learner to follow the demonstration, to practice and to appreciate its progression.

We present here the results of the competences related to the prevention and the management of the immediate postpartum haemorrhage by uterine atony. These included the active management of the third stage of labor (AMTSL), the manual removal of the placenta in the case of placental retention, the management of immediate postpartum haemorrhage by uterine atony and the uterine bimanual compression. For each of these skills, a clinical situation was presented; the provider performed the tasks of the competence. At the end of the training in the classroom, two formative supervision visits on the site of each provider made it possible to complete the training in real situations. This article reports the results of the first phase; the visits to the site have not yet been completed.

\subsection{Teaching Material}

Two teaching manuals were used: a reference manual published by the World Health Organization [3] and a trainer's guide developed and validated by the Health Ministry. Numerous anatomical models (Figure 1) as well as equipments and consumables were used to make the clinical situations of the different stations as realistic as possible.

\subsection{Assessment Method}

The theoretical evaluation consisted of the administration of a prior questionnaire and a mid-stage questionnaire. A performance of at least $85 \%$ was required. The practical evaluation used a checklist and included an initial, midterm and a final assessment for each skill. A computerized database generating graphs was filled. During the formative supervision on the provider's site, the trainer, using the same checklists, assessed the performance of the provider in real-life situations, thus allowing the database to be filled. The claimant was declared competent after passing the theoretical assessment and practical classroom assessments and during the two formative supervision visits. 

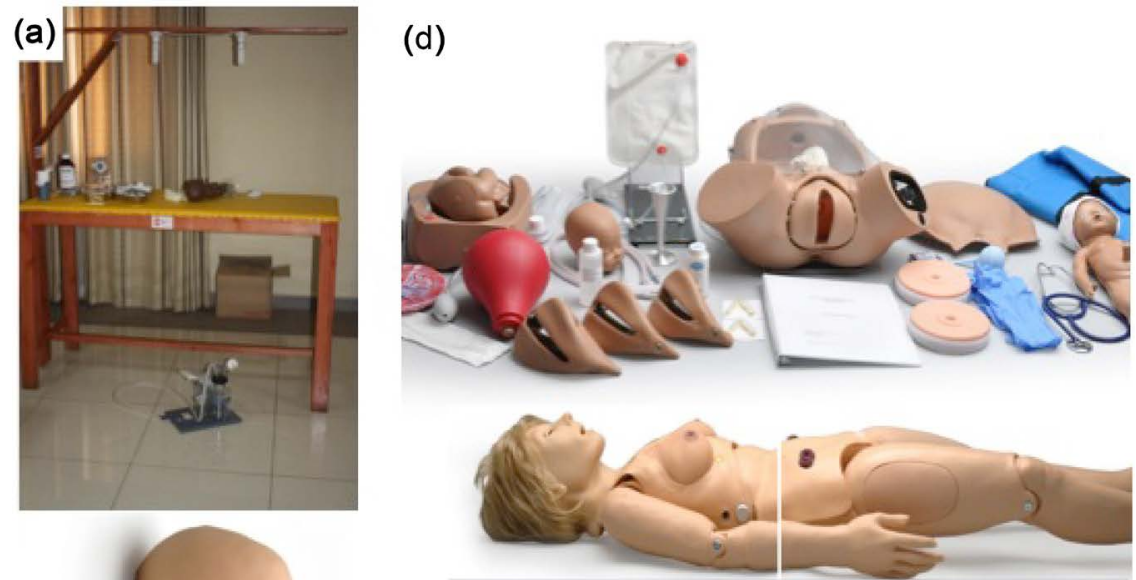

(b)
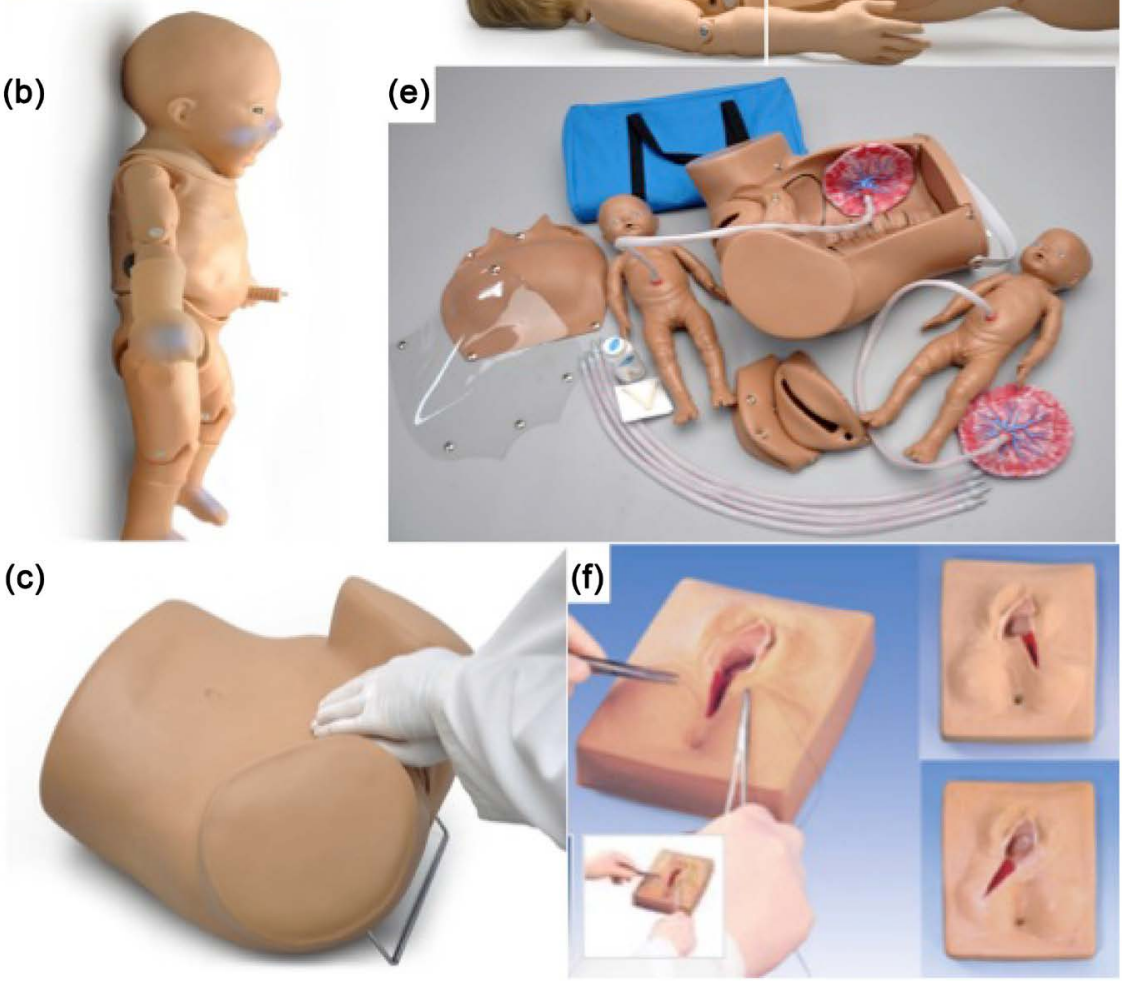

Figure 1. Training models [10]. Simulation models. (a) Neonatal resuscitation table of artisanal manufacture; (b) Newborn resuscitation model (Gaumard); (c) Anatomical model for manual aspiration intrauterine; (d) Set of simulation and treatment of postpartum hemorrhage; (e) Birthing model and articulated fetus; (f) Episiotomy repair model (3B Scientific).

\section{Results}

A total of 432 providers were trained according to this approach between July and December 2015 after 25 training sessions.

The majority of the participants were midwives (97.4\%). The others were nurses.

Mean initial assessment of the 432 participants for AMTSL, manual placenta extraction, management of immediate postpartum haemorrhage by uterine atony and bimanual compression of the uterus were $51.1 \%, 46 \%, 29.3 \%$ and $17.8 \%$ respectively (Figure 2 ). The average of $85 \%$ judged to be minimal to vali- 
date competence was reached by almost all participants in the mid-term evaluation with an average of $94.5 \%, 94 \%, 94.6$ and $94.2 \%$ for 4 skills respectively. Only those participants who did not validate a competency at the mid-term evaluation (score $<85 \%$ ) resumed the training after a training session. They validated the competence upon obtaining a mark of $85 \%$ or more. Figure 3 shows the results of the final evaluation.

\section{Discussion}

Obstetricians and midwives face extreme emergencies that need to be managed quickly, efficiently and in a team environment. These situations, which are often rare, are serious and must be dealt with by experienced staff. Yet, because of the increasing number of learners and the scarcity of teachers in maternity hospitals, exposure to critical situations has become less frequent. In this study, we identified the inability of some providers to identify obstetric emergencies. Management was affected by the lack of technical skills, but also the importance of interpersonal and interdisciplinary communication problems. Haemorrhage is the most important cause of maternal death in the world. More than half of all

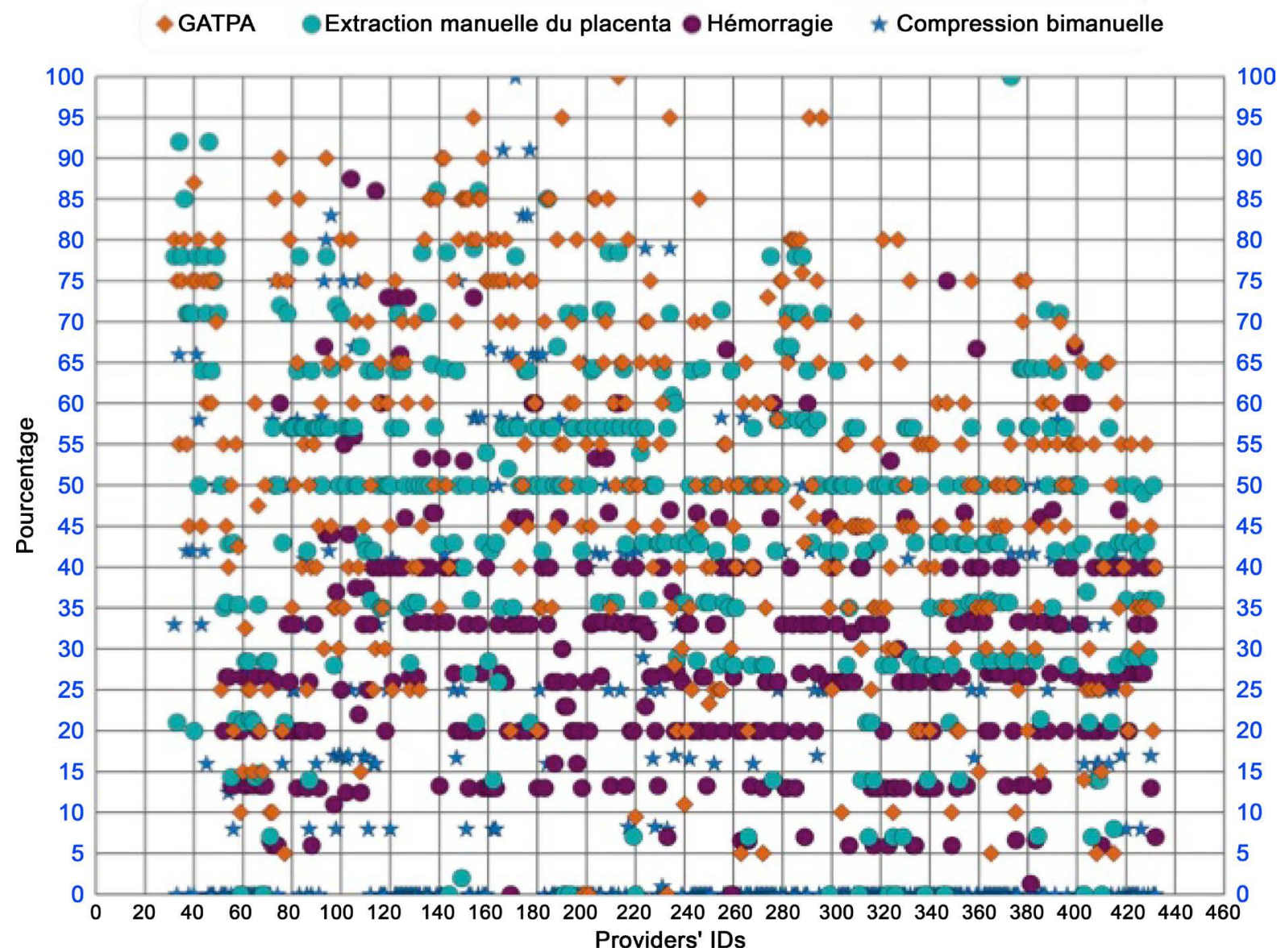

GATPA: Active management of the third stage of labor; Extraction manuelle du placenta: Manual removal of the placenta; Hémorragie: Management of immediate postpartum haemorrhage by uterine atony; Compression bimanuelle: Uterine bimanual compression.

Figure 2. Distribution of participants according to initial assessment. 


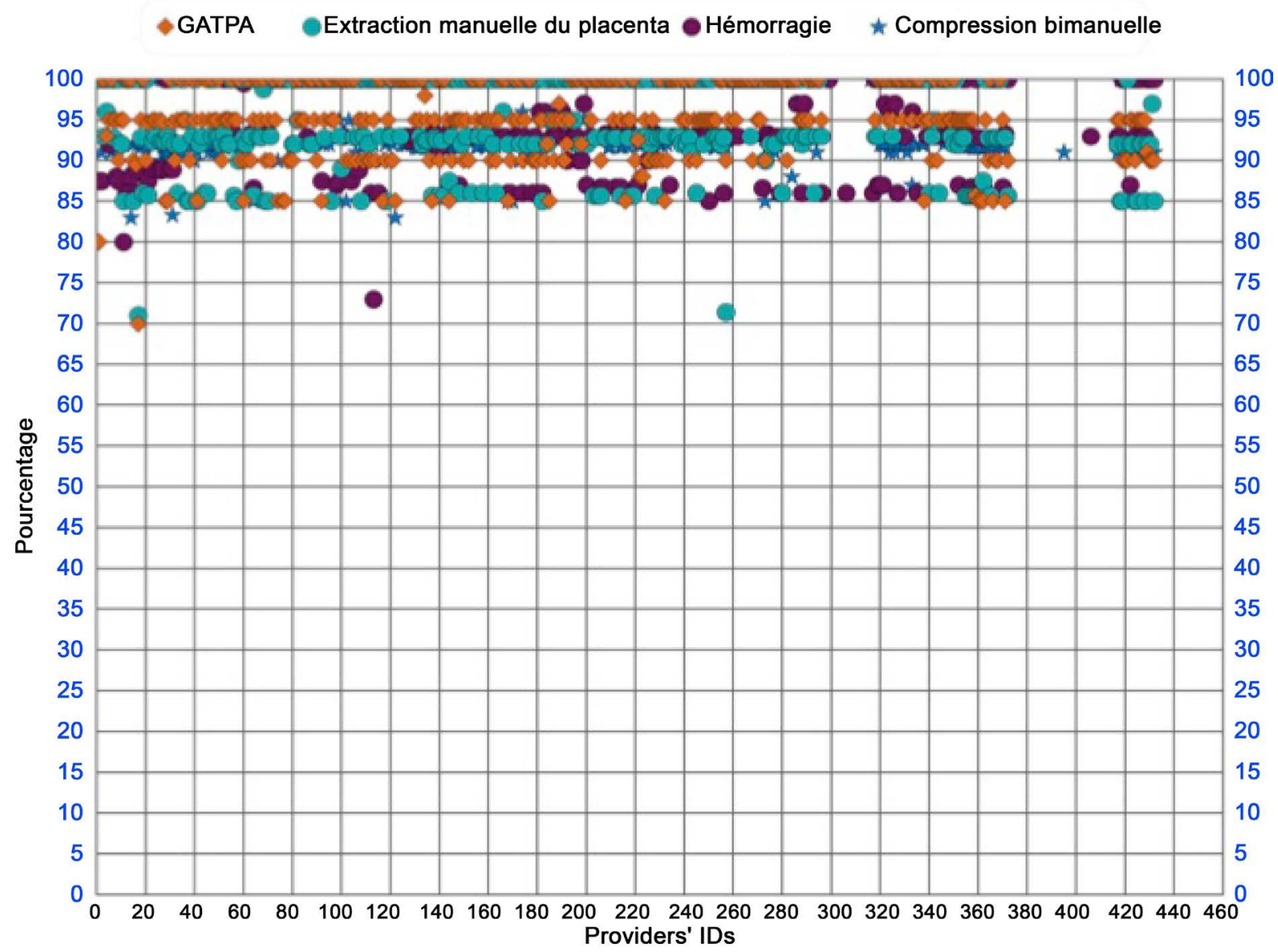

GATPA: Active management of the third stage of labor; Extraction manuelle du placenta: Manual removal of the placenta; Hémorragie: Management of immediate postpartum haemorrhage by uterine atony; Compression bimanuelle: Uterine bimanual compression.

Figure 3. Distribution of participants according to midterm and final assessments.

maternal deaths occur within 24 hours of childbirth, mostly due to excessive bleeding. Any pregnant woman may face a blood loss that could endanger her life at the time of delivery; anemic women are particularly vulnerable because they may not even tolerate moderate blood loss. All women should be closely monitored and stabilized as needed during the immediate postpartum period. Following a review of available evidence, the International Federation of Obstetricians and Gynaecologists (FIGO) and the International Confederation of Midwives (ICM) agree that the active management of the third stage of labor has proved effective to reduce the incidence of postpartum haemorrhage (PPH), the amount of blood loss and the use of blood transfusions [4] [5] [6] [7].

This practice is widespread throughout the national territory following continuous training of all midwives in Senegal through training sessions led by the Ministry of Health, sometimes accompanied by non-governmental organizations. We expected a much higher skill achievement percentage. But this was only $51.1 \%$ with very disparate scores ranging from $0 \%$ to $100 \%$. This finding is alarming and explains the still high prevalence of haemorrhage in obstetric complications and maternal deaths in our country. Some steps in the technique 
such as the placenta examination were not properly performed by any participant. However, a brief review of the technique and the demonstration almost in a real situation made it possible to rectify certain gestures in the realization of the competence and to systematize the procedure; as evidenced by the average score at the midterm evaluation of $94.5 \%$. In the event of AMTSL failure, manual removal of the placenta is recommended. Fortunately, the indication was known to all participants. However, two essential steps in the procedure were problems: antibiotic administration and analgesia. It should be noted that the Senegalese health system only provides for the presence of anaesthetists (doctors or senior technicians) in level 2 health centres or hospitals. Some providers working in health posts or level 1 health centres are not in contact with anaesthetists and are regularly confronted with serious obstetric emergencies such as placental retention. The alternative in this situation is to administer $10 \mathrm{mg}$ of Diazepam to promote a slight sedation in order to facilitate the gesture. Interpersonal communication also facilitates the process.

Postpartum haemorrhage, which is the main obstetric complication, was the subject of a station in its most frequent variant: uterine atony. We felt it was more relevant, more frequent and more systematic. Only two out of 432 participants had attained the initial rating for the 15-step skill, using teamwork skills and basic gestures in maternal resuscitation. Participants realized after the demonstration that small gestures could make a difference and that systematization and teamwork were crucial in the management of obstetric emergencies. A study conducted in 2007 showed that training by simulation could highlight the various dysfunctions during obstetric emergencies. The postpartum haemorrhage scenario was repeated within six months and demonstrated an improvement in the management of this complication [8]. Birch compared three methods of teaching and training postpartum haemorrhage: courses, simulation and mixed teaching courses and simulation. The scores evaluated were higher after the different courses but better for the mixed method. It is also in this group that one finds the best perception of the theoretical knowledge acquired, the highest level of confidence and the lowest level of anxiety [9]. The bimanual compression technique was a new skill for most participants but was easy to master with averages after demonstration reaching easily more than $90 \%$.

\section{Conclusion}

The simulated practice ensures the learning and mastery of all the skills of the EONC and minimizes the risks during the practice in patients. The main challenge remains twofold: to document the impact of this training on emergency obstetric care indicators and to integrate this training modality into basic training (medical school, midwifery school).

\section{References}

[1] Sullivan, R. (1995) Compétences en formation clinique pour les professionnels de santé de la reproduction. JHPIEGO Corporation, Baltimore. 
[2] van den Broekn, N. (2007) Life Saving Skills Manual. RCOG, London.

[3] World Health Organisation (2004) Prise en charge des complications de la grossesse et de l'accouchement: guide destiné à la sage-femme et au médecin. Genève.

[4] WHO, UNFPA, UNICEF, Bank W. (2000) Managing Complications in Pregnancy and Childbirth. WHO/RHR/00.7, Geneve.

[5] Elbourne, D.R., Prendiville, W.J., Carroli, G., Wood, J., McDonald, S., Elbourne, D.R., Prendiville, W.J., Carroli, G., Wood, J. and McDonald, S. (2003) Prophylactic Use of Oxytocin in the Third Stage of Labour. The Cochran Library, Oxford, No. 3.

[6] Prendiville, W.J., Elbourne, D. and McDonald, S. (2003) Active vs. Expectant Management in the Third Stage of Labour. The Cochran Library, Oxford, No. 3.

[7] Joy, S.D., Sanchez-Ramos, L. and Kaunitz, A.M. (2003) Misoprostol Use during the Third Stage of Labor. International Journal of Gynecology \& Obstetrics, 82,143-152. https://doi.org/10.1016/S0020-7292(03)00146-2

[8] Maslovitz, S., Barkai, G., Lessing, J.B., Ziv, A. and Many, A. (2007) Recurrent Obstetric Management Mistakes Identified by Simulation. Obstetrics \& Gynecology, 109, 1295-1300. https://doi.org/10.1097/01.AOG.0000265208.16659.c9

[9] Birch, L., Jones, N. and Doyle, P.M. (2007) Obstetric Skills Drills: Evaluation of Teaching Methods. Nurse Education Today, 27, 915-922.

https://doi.org/10.1016/j.nedt.2007.01.006

[10] Gueye, M., Moreira, P.M., Faye-Dieme, M.E., Ndiaye-Gueye, M.D., Gassama, O., Kane-Gueye, S.M., et al. (2017) Simulation Training for Emergency Obstetric and Neonatal Care in Senegal Preliminary Results. Médecine et Santé Tropicales, 27, 131-134. 